\title{
Stroke Management Awareness and Behavior among Nursing Students in Bangladesh
}

\author{
Shariful Islam, Eui Geum Oh, Tae Wha Lee, Sanghee Kim* \\ College of Nursing, Yonsei University, Seoul, South Korea \\ Email: ishariful791@gmail.com, euigeum@yuhs.ac, twlee5@yuhs.ac, *sangheekim@yuhs.ac
}

How to cite this paper: Islam, S., Oh, E.G., Lee, T.W. and Kim, S. (2017) Stroke Management Awareness and Behavior among Nursing Students in Bangladesh. Open Journal of Nursing, 7, 1-14. http://dx.doi.org/10.4236/ojn.2017.71001

Received: December 6, 2016

Accepted: January 9, 2017

Published: January 12, 2017

Copyright (๑) 2017 by authors and Scientific Research Publishing Inc. This work is licensed under the Creative Commons Attribution International License (CC BY 4.0).

http://creativecommons.org/licenses/by/4.0/ cc) (i) Open Access

\begin{abstract}
Background: Stroke is a significant cause of morbidity and mortality throughout the world. In Bangladesh, stroke accounts for $27 \%$ of deaths, making it the third leading cause of death and disability [1]. Nurses have a critical role to play in reducing death and disability among stroke victims, but many nursing students are not being educated to meet the challenges of this complex condition. Objectives: This study examined undergraduate nursing students' awareness of strokes and their stroke patient management behaviors. Method: This was a descriptive study that surveyed undergraduate nursing students about their awareness of strokes and stroke patient management behaviors. One hundred and forty-four students were recruited from Dhaka University's and Rajshahi University's nursing colleges in Bangladesh. The students completed and returned the Awareness of Stroke Risk Factors, Awareness of Stroke Warning Signs, and Behavior of First Responses to Strokes and Behaviors of Special Managements of Stroke questionnaires between December, 2014 and February, 2015. Data were analyzed using descriptive statistics and the Pearson's Product-Moment Correlation-Coefficient. Results: The results showed that nursing students had a moderate awareness level of stroke risk factors $(\mathrm{M}=74.24, \mathrm{SD}=12.30)$ and a very low awareness of stroke warning signs $(M=55, S D=10.72)$. In addition, all of the students had a low to very low level of behaviors of special stroke patient management $(\mathrm{M}=62.11, \mathrm{SD}=$ 9.75) and a very low level of behaviors of first responses to strokes $(M=0.24$, $\mathrm{SD}=0.43)$. There was a significant positive correlation between nursing students' awareness of stroke risk factors and stroke warning signs $\left(r=0.247^{\star *}, \mathrm{p}\right.$ $<0.001)$. However, no significant correlation was found between students' awareness of stroke risk factors with their behaviors of first responses to strokes $(r=0.043, p>0.05)$. In addition, their awareness of stroke warning signs was not correlated with their behaviors of special stroke patient management $(\mathrm{r}=$ $0.031, \mathrm{p}>0.05)$. These findings suggested that nursing students need to increase their awareness level to develop stroke management behaviors in order to improve practicum preparedness. Conclusion: Work-based education must
\end{abstract}


be a part of nursing students' curricula to increase their awareness of strokes and improve their stroke management behaviors to improve practicum preparedness.

\section{Keywords}

Stroke, Nursing Students, Awareness, Behavior, Stroke Management

\section{Introduction}

Stroke is the sudden focal neurological dysfunction caused by the blockage or ruptures of a blood vessel in the brain and is a significant cause of morbidity and mortality throughout the world [2]. In Bangladesh, stroke accounts for $27 \%$ of deaths and is the third leading cause of death and disability [1], accountings for $11.9 \%$ of deaths globally [3]. Stroke has severely negative effects on the quality of life of those who suffer from it, imposing significant burdens on society [4]. Stroke induces negative follow-on effects, including an increased risk of infection, mortality, use of hospital resources, patient care costs, and length of hospital stays and a decreased quality of life [4]. Nurses can play a critical role in reducing death and disability resulting from stroke by identifying risk factors and warning signs to manage the effects of strokes [5].

The occurrence of stroke is associated with lower socioeconomic status and certain lifestyle factors, including smoking, a poor diet, and limited physical activity [6]. It has been estimated that an aging population has caused an increase in the prevalence of major risk factors, including hypertension, diabetes mellitus, and obesity, causing the incidence of stroke to double by 2020 [4]. The most important factors influencing the impact of strokes are nurses' awareness of risk factors, stroke warning signs, their behaviors of first responses to strokes, and behaviors about how to manage stroke victims. One study indicated that emergency nurses were mostly unaware of evidence-based interventions that have been proven to help mitigate and manage the effects of strokes [7]. However, in Bangladesh, there is still a recognized lack of awareness of strokes and stroke management behaviors among undergraduate nursing students, but these students are not alone in their ignorance. International studies indicate that nurses in India, South Korea, Hong Kong, Brazil, Australia, and France are also unaware of the warning signs of and risk factors for strokes [8]-[13].

Nurses who treat stroke patients require extensive education and training in order to deliver quality patient-focused care [14]. However, as indicated above, students often do not receive the necessary education to be able to provide this care. Edwards has observed that nurses of stroke patients often felt ill prepared by their preregistration education [15]. However, students have expressed the importance of being equipped with a sound foundation in stroke awareness before entering clinical practice [16].

To increase students' awareness of and how to manage strokes, nursing stu- 
dents must receive more practical stroke management experience as part of their practicum preparedness [16]. A previous study has indicated that work-based educational programs are necessary for equipping students with the necessary skills to manage their stroke patients [14]. However, few studies have specifically examined nursing students' awareness of strokes and stroke management behaviors. This study seeks to help fill that knowledge gap. The results of the study indicate how nursing education should be redesigned in order to increase students' stroke management clinical competency.

\section{Conceptual Framework}

This study's conceptual framework was based on the Bloom educational objective taxonomy [17] as modified by Anderson and Krathwohl [18]. In addition, the knowledge-attitude-practice (KAP) model [19] and the existing stroke management literature were used to guide the relationship between awareness, and behavior. According to Bloom, there are three educational objective domains: cognitive, affective, and psychomotor. Knowledge and awareness, attitude and affect, and practice and behavior represent each domain respectively. Within the cognitive domain, knowledge refers to factual, conceptual, procedural, and metacognitive thought while awareness is the mechanism by which one reaches different levels of knowledge. By combining these two dimensions, there are six levels within the cognitive domain: remembering, understanding, applying, analyzing, evaluating, and creating. First three levels are: 1) Remembering is described as retrieving, recognizing, and recalling relevant knowledge from long term memory, 2) Understanding is the meaning, translation, and interpretation of instructions and problems, and 3) Applying is defined as the carrying out or using a procedure through executing or implementing. Within the affective domain, attitude is the cognitive reaction to a perceived event and has five levels: receiving, responding, valuing, organizing, and internalizing [20]. The first three levels includes: 1) Receiving explains awareness, willingness to hear, and selected attention towards the phenomenon, 2) Responding is meant to attend and react to a particular phenomenon, and 3) Valuing is an internalization of a set of specified values which were expressed by an individual's overt behavior. Behavior, a psychomotor domain, refers to the physical movement, coordination and use of motor or neuromuscular activities. This domain is categorized into five levels: imitation, manipulation, precision, articulation, and naturalization. The first three levels are: 1) Imitation covers observing and patterning behavior after someone else, 2) Manipulation is an individual's ability to perform certain actions by following written or verbal instructions, and 3) Precision is an individual's ability to perform a task or activity with expertise and to deliver high quality care without assistance or instructions.

According to Bloom, the first level is the prerequisite to the next, meaning that one cannot effectively address the higher level if they do not learn the below ones. First three levels of each domain are the lower levels of learning, which this study focused on to examine students' foundational levels of awareness and be- 
havioral development.

In Bangladesh, nursing students have been trained to provide fundamentals of nursing care, which require the first three levels of learning objectives of each domain. Thus, it is more reasonable to assess them whether Bangladeshi nursing students possess the first three levels in the learning domains. Figure 1 shows the first three levels of each domain and how they are manifested in stroke management awareness and behavior. According to KAP model, if an individual is aware of certain things, such awareness can greatly influence that individual's ability to perform an action. So the first three levels of awareness and behavior were the key categories for representing nursing students' fundamental stroke management practices in this study.

\section{Methods}

\subsection{Study Design}

This study was a descriptive survey designed to explore nursing students' awareness of stroke and stroke management behaviors and the connection between these two variables.

\subsection{Sample and Setting}

The participants were a sample selected from fourth-year undergraduate nursing students who could read and understand Bengali in Dhaka University's and Rajshahi University's nursing colleges to reduce college size-specific characteristics. Post-basic B.Sc. nursing students were excluded. The sample size was determined by using G-Power version 3.1 with an acceptable level of significance of $\alpha<0.05$, a test power of 0.80 , and a medium effect size of 0.25 . In order to avoid experimental failure because of attrition, $20 \%$ more subjects were recruited than were statistically required [21]. A total of 144 questionnaires were distributed to the two sample populations between December, 2014 and February, 2015, all of which were completed and returned. Most of the students had been placed in medicine, neuromedicine, and ICU practicum courses because of their curricula's designs.

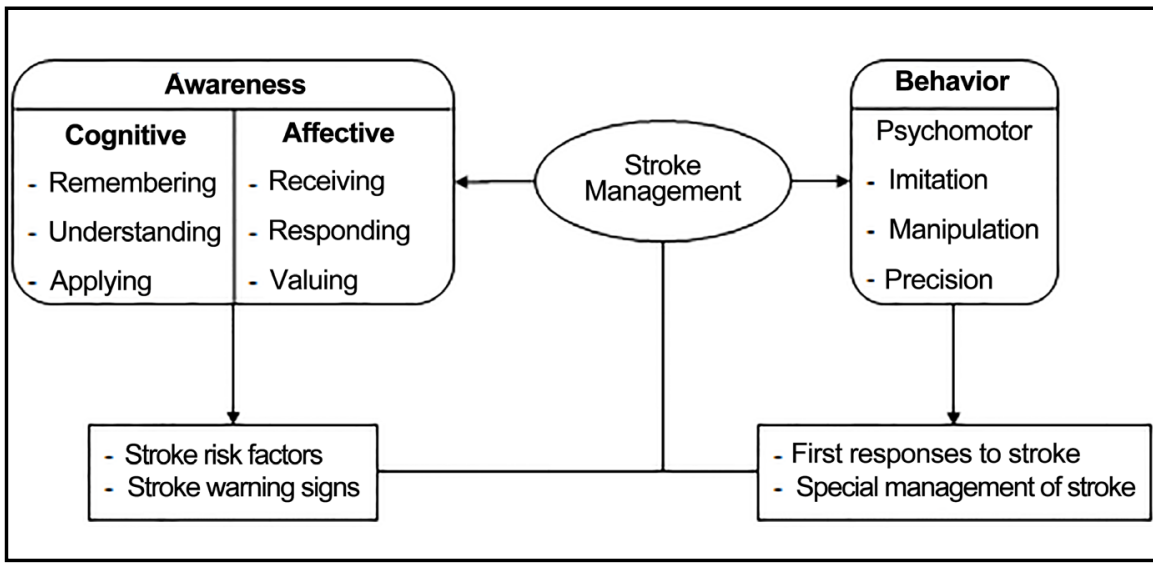

Figure 1. Conceptual framework of the study. 


\subsection{Ethical Considerations}

This study received approval (2015-00003) from the Institutional Review Board of the College of Nursing, Yonsei University, 50 Yonsei-ro, Seodemun-gu, Seoul, South Korea. The purpose of the research was explained in advance to the participants who gave written informed consent based on premise that their participation in the study would be voluntary. The participants were informed of their right to withdraw from the study any time. They confirmed their understanding that the primary data only would be used for research purposes and that their anonymity was guaranteed. The participants were also informed that the completed questionnaires would be kept by the research team during the study period but would be destroyed upon completion of the study. Small gifts of snacks and stationery were provided to the students as compensation for their participation.

\subsection{Instruments}

The instruments used in this study were as follows: 1) Awareness of Stroke Risk Factors Questionnaire (ASRFQ), 2) Awareness of Stroke Warning Signs Questionnaire (ASWSQ), and 3) Behaviors of First Responses to Strokes Questionnaire (BFRSQ), 4) Behavior of Special Management of Stroke Questionnaire (BSMSQ), and 5) a demographic questionnaire.

\subsubsection{Nursing Student's Awareness of Stroke Risk Factors}

Nursing student awareness of stroke risk factors was assessed using the 20-item ASRFQ which allowed respondents to answer "true", "false", or "don't know". The inventory was based on the decision-tree analysis model developed by Kim, Jeong, and Kang [22] and was further modified and developed by the research team. Each correct answer received one point while incorrect answers received zero points. Respondents could receive a total of between 0 and 20 points, which was then converted into a percentage. Higher scores indicated higher levels of awareness of stroke risk factors. The Cronbach's alpha of the total ASRFQ was 0.84 [22] for the Korean version. In this study, the measures of internal consistency for risk factors in the related questionnaire were yielded at a Cronbach's alpha of 0.92 .

\subsubsection{Nursing Student's Awareness of Stroke Warning Signs}

Nursing student awareness level of stroke warning signs was assessed using the 16-item ASWSQ based on decision-tree analysis model [22] modified by the research team. The respondents were allowed to answer "true", "false", or "don't know". Each correct answer received one point while incorrect answers received zero points. Respondents could receive a total of between 0 and 16 points, which was then converted into a percentage. Higher scores indicated higher levels of awareness of stroke warning signs. The Cronbach's alpha of the total ASWSQ was 0.84 [22] for the Korean version. In this study, the measures of internal consistency for stroke warning signs in the related questionnaire were yielded at a Cronbach's alpha of 0.81 . 


\subsubsection{Nursing Student's Behaviors of First Responses to Strokes}

Nursing student behaviors of first responses to strokes were assessed using the single-item BFRSQ with 5 choices based on the work done by Kim, Jeong and Kang [22]. Each correct answer received one point while incorrect answers received zero points. Higher scores indicated a greater ability to make appropriate first responses to strokes. The Cronbach's alpha for this section was 0.86 for the Korean version. In this study, the measures of internal consistency for behavior to take appropriate first responses to strokes in the related questionnaire were yielded at a Cronbach's alpha of 0.86 .

\subsubsection{Nursing Student's Ability to Specially Manage Stroke Patients}

Nursing student ability to specially manage stroke patients was assessed using the 30-item BSMSQ, which was developed by the research team. The subjects were allowed to answer "true", "false", or "don't know". Each correct answer received one point while incorrect answers received zero points. Respondents could receive a total of between 0 and 30 points, which was then converted into a percentage. Higher scores indicated a greater ability to specially manage stroke patients. In this study, the measures of internal consistency for ability to specially manage stroke patients in the related questionnaire were yielded at Cronbach's alpha of 0.86 .

\subsubsection{Demographic Questionnaire}

The nursing student demographic questionnaire was developed by the research team based on a review of existing literature. This questionnaire included questions on sex, age, student status, religion, marital status, and clinical experience.

\subsection{Data Collection}

A descriptive design was employed. After getting permission from the class teachers of two nursing colleges and at the end of selected classes, the researcher introduced the objectives of the study to the students. The self-administered questionnaires, small gifts and box were kept on a desk outside of the classroom. Students interested in participating in the study were invited to pick up a flyer or a set of questionnaires from outside of the classroom on a first-come, firstserved basis. Participants needed approximately 20 minutes to complete the questionnaires. The students were instructed to drop the completed questionnaire into the box. Based on collection of the completed questionnaire from the box, 144 students were considered as eligible subjects who signed written informed consent form in this study. Students could be withdrawn participation at any time if they could wish to, with no risk to their educational opportunity or grades.

\subsection{Data Analysis}

Data were analyzed using SPSS version 21.0. Before conducting the analysis, the data were examined for outliers and missing responses. Data were analyzed using descriptive and inferential statistics. Correlational analysis between the scores 
on the stroke awareness and stroke management behavior questionnaires was performed using Pearson's Product Moment Correlation Coefficients. One-way ANOVA tests and t-tests were used to determine the relationship between nursing students' demographic characteristics and their awareness of stroke and stroke management behaviors.

\section{Results}

\subsection{Demographic Characteristics}

Table 1 summarizes the participating students' demographic characteristics. The mean age of the students was $21.87 \pm 0.75$ years old with a range of 20 to 24 years old. Most of the students were between 20 and 22 years old (82.6\%). The majority of the students were Muslim (86.1\%) and a minority of them were Hindu (13.9\%). The students were mostly female (93.8\%). Most of them were single (97.9\%). No student reported prior stroke management clinical experience, but all students had heard of strokes before.

\subsection{Nursing Student's Awareness of Stroke Background Information}

Nursing student awareness of stroke background information was sub-divided according to their awareness of stroke risk factors and stroke warning signs.

\subsubsection{Nursing Student's Awareness of Stroke Risk Factors}

Table 2 shows the frequency, percentage, mean, and SD of nursing students' scores in each category of awareness level of stroke risk factors. The majority of the students (59.1\%) had a moderate or high level of awareness regarding stroke risk factors $(\mathrm{M}=74.24, \mathrm{SD}=12.30)$ with a range of $45 \%$ to $100 \%$. Very few of them had a low $(8.3 \%)$ to a very low (16.7\%) level of awareness of stroke risk factors. The least number of students (12.5\%) had a high level of awareness of stroke risk factors.

Table 1. Demographic characteristics of participating students $(\mathrm{N}=144)$.

\begin{tabular}{ccccc}
\hline Characteristics & Categories & $\mathrm{n}$ & $\%$ & $\mathrm{M} \pm \mathrm{SD}$ \\
\hline \multirow{2}{*}{ Sex } & Male & 09 & 6.3 & $1.94 \pm 0.24$ \\
& Female & 135 & 93.8 & \\
Age (years) & $20-22$ & 119 & 82.6 & $21.87 \pm 0.75$ \\
& $23-24$ & 25 & 17.4 & \\
Student type & $4^{\text {th }}$ year & 144 & 100 & \\
& undergraduate & & & \\
& Muslim & 124 & 86.1 & \\
Religion & Hindu & 20 & 13.9 & $1.14 \pm 0.34$ \\
& Christian & 00 & 0.0 & \\
& Buddhist & 00 & 0.0 & $1.02 \pm 0.14$ \\
& Single & 141 & 97.9 & \\
\hline
\end{tabular}




\subsubsection{Nursing Student's Awareness of Stroke Warning Signs}

Table 3 shows the frequency, percentage, mean, and SD of nursing students' scores in each category of awareness level of stroke warning signs. Most students (95.1\%) had a low or very low level of awareness of stroke warning signs ( $\mathrm{M}=$ $55.01, \mathrm{SD}=10.72)$ with a range of $31 \%$ to $81 \%$. The least number of students had a moderate $(1.4 \%)$ to high $(0.2 \%)$ level of awareness of stroke warning signs.

\subsection{Nursing Student's Stroke Management Behaviors}

Nursing students' stroke management behaviors was sub-divided into behavior of first responses to strokes and special stroke patient management behaviors.

\subsubsection{Nursing Student's Behaviors of First Responses to Strokes}

Table 4 shows the frequency, percentage, mean and SD of nursing students' scores in each category for their behaviors of first responses to strokes. The results revealed that most of the students (75.7\%) had a very low level of behaviors $(\mathrm{M}=0.24, \mathrm{SD}=0.43)$ about the first responses that they should have to strokes. Very few (24.3\%) of them showed a very high level of behaviors about the first response to strokes. A majority of the students (63.9\%) had answered the questions incorrectly whereas a minority of them $(35.4 \%)$ answered correctly.

Table 2. Frequency, percentage, mean, and SD of students' scores in each category of awareness level of stroke risk factors $(\mathrm{N}=144)$.

\begin{tabular}{cccc}
\hline Awareness Level of Stroke Risk Factors & $\mathrm{n}$ & $\%$ & $\mathrm{M} \pm \mathrm{SD}$ \\
\hline Very low $(<60 \%)$ & 24 & 16.7 & \\
Low $(60 \%-69.99 \%)$ & 12 & 8.3 & $74.24 \pm 12.30$ \\
Moderate $(70 \%-79.99 \%)$ & 42 & 29.2 & \\
High $(80 \%-89.99 \%)$ & 43 & 12.5 & \\
Very high $(90 \%-100 \%)$ & 18 & & \\
\hline
\end{tabular}

Table 3. Frequency, percentage, mean, and SD of students' scores in each category of awareness level of Stroke Warning Signs $(\mathrm{N}=144)$.

\begin{tabular}{cccc}
\hline Awareness Level of Stroke Warning Signs & $\mathrm{n}$ & $\%$ & $\mathrm{M} \pm \mathrm{SD}$ \\
Very low $(<60 \%)$ & 91 & 63.2 & \\
Low $(60 \%-69.99 \%)$ & 46 & 31.9 & $55.01 \pm 10.72$ \\
Moderate $(70 \%-79.99 \%)$ & 02 & 0.4 & \\
High $(80 \%-89.99 \%)$ & 01 & - \\
Very high $(90 \%-100 \%)$ & - & \\
\hline
\end{tabular}

Table 4. Frequency, percentage, mean and SD of students in each category of behavior level of first responses to Strokes $(\mathrm{N}=144)$.

\begin{tabular}{cccc}
\hline Behaviors Level of First Responses to Strokes & $\mathrm{n}$ & $\%$ & $\mathrm{M} \pm \mathrm{SD}$ \\
\hline Very low $(<60 \%)$ & 109 & 75.7 & $0.24 \pm 0.43$ \\
Very high $(90 \%-100 \%)$ & 35 & 24.3 & \\
\hline
\end{tabular}


3.3.2. Nursing Student's Behaviors of Special Stroke Patient Managements Table 5 shows the frequency, percentage, mean, and SD of nursing students' scores in each category of behaviors of special stroke patient managements. The findings showed that majority of the students $(76.4 \%)$ had a low or a very low level of behaviors about special stroke patient managements $(\mathrm{M}=62.11, \mathrm{SD}=$ 9.75) with a range of 37 to 87 . However, a small number of the students (17.4\%) had a moderate level of behaviors and the least number of them (4.9\%) had high level of behaviors about special stroke patient managements.

\subsection{Behaviors of First Responses to Strokes, and Behaviors of Special Stroke Patient Managements ( $\mathrm{N}=144)$}

Table 6 shows the descriptive statistics about nursing students' awareness of stroke risk factors, awareness of stroke warning signs, behaviors of first responses to strokes and behaviors of special stroke patient managements. Nursing students' awareness of stroke risk factors had a mean score of $14.85(\mathrm{SD}=2.46)$ with a range of 9 to 20. For awareness of stroke warning signs, the mean score was $8.80(\mathrm{SD}=1.71)$ with a range of 5 to 13 . For behaviors of first responses to strokes, the mean score was $0.36(\mathrm{SD}=0.48)$ with a range of 0 to 1 . For behaviors of special stroke patient managements, the mean score was 18.65 ( $\mathrm{SD}=$ 2.98) with a range of 11 to 26.

\subsection{Differences in Awareness of Stroke Risk Factors, Awareness of Stroke Warning Signs, Behaviors of Special Stroke Patient Managements According to Demographic Characteristics}

Table 7 shows the differences in students' awareness of stroke risk factors, awareness of stroke warning signs, and behaviors of special stroke patient managements according to demographic characteristics. Muslim Students had a higher level of awareness of stroke warning signs $(r=0.35, \mathrm{p}<0.036)$ that non-Muslim students.

\subsection{Relationship among Awareness of Stroke Risk Factors, Awareness of Stroke Warning Signs, and Behaviors of Special Stroke Patient Managements}

Table 8 shows a significant positive correlation between nursing students' awareness of stroke risk factors and awareness of stroke warning signs $\left(r=0.247^{\star *}, \mathrm{p}\right.$ $=0.004)$. Students' awareness of stroke risk factors was significantly negatively

Table 5. Frequency, percentage, mean, and SD of nursing students' behaviors of special stroke patient managements in each category $(\mathrm{N}=144)$.

\begin{tabular}{cccc}
\hline Behaviors Level of Special Stroke Patient Managements & $\mathrm{n}$ & $\%$ & $\mathrm{M} \pm \mathrm{SD}$ \\
\hline Very low $(<60 \%)$ & 61 & 42.4 & $62.11 \pm 9.75$ \\
Low $(60 \%-69.99 \%)$ & 49 & 34.0 & \\
Moderate $(70 \%-79.99 \%)$ & 25 & 17.4 & \\
High $(80 \%-89.99 \%)$ & 07 & 4.9 & \\
Very high $(90 \%-100 \%)$ & & & \\
\hline
\end{tabular}


Table 6. Descriptive statistics for nursing students' awareness of stroke risk factors, awareness of stroke warning signs, behaviors of first responses to strokes and behaviors of special stroke patient managements $(\mathrm{N}=144)$.

\begin{tabular}{cccc}
\hline Variables & Category & Total Item & Range \\
\hline Awareness of Stroke Risk Factors & Stroke risk factors & $14.85 \pm 2.46$ & $9-20$ \\
$\begin{array}{c}\text { Awareness of Stroke } \\
\text { Warning Signs }\end{array}$ & Stroke warning signs & $8.80 \pm 1.71$ & $5-13$ \\
$\begin{array}{c}\text { Behaviors of First Responses } \\
\text { to Strokes }\end{array}$ & $\begin{array}{c}\text { First responses to } \\
\text { strokes }\end{array}$ & $0.36 \pm 0.48$ & $0-1$ \\
$\begin{array}{c}\text { Behaviors of Special Stroke } \\
\text { Patient Managements }\end{array}$ & $\begin{array}{c}\text { Special stroke patient } \\
\text { managements }\end{array}$ & $18.63 \pm 2.92$ & $11-26$ \\
\hline
\end{tabular}

Table 7. Descriptive statistics for awareness of risk factors, awareness of warning signs, and behaviors of special stroke management according to demographic characteristics ( $\mathrm{N}$ =144).

\begin{tabular}{ccccc}
\hline Characteristics & Categories & $\begin{array}{c}\text { Risk factors } \\
(\mathrm{M} \pm \mathrm{SD})\end{array}$ & $\begin{array}{c}\text { Warning signs } \\
(\mathrm{M} \pm \mathrm{SD})\end{array}$ & $\begin{array}{c}\text { Special stroke } \\
\text { management } \\
(\mathrm{M} \pm \mathrm{SD})\end{array}$ \\
\hline Age group & $20-22$ Years & $14.93 \pm 2.505$ & $8.81 \pm 1.732$ & $18.64 \pm 3.031$ \\
& $23-24$ Years & $14.43 \pm 2.233$ & $8.75 \pm 1.675$ & $18.58 \pm 2.394$ \\
Religion & Muslim & $14.71 \pm 2.457$ & $8.64 \pm 1.565$ & $18.67 \pm 2.990$ \\
$\begin{array}{c}\text { First Responses } \\
\text { to Strokes }\end{array}$ & Non-Muslim & $15.65 \pm 2.390$ & $9.80 \pm 2.238$ & $18.37 \pm 2.521$ \\
& Correct & $14.88 \pm 2.251$ & $9.10 \pm 1.876$ & $19.12 \pm 2.775$ \\
& Behavior & & & \\
& Incorrect & $14.81 \pm 2.584$ & $8.66 \pm 1.609$ & $18.35 \pm 2.998$ \\
\hline & Behavior & & & \\
\hline
\end{tabular}

Table 8. Correlation between nursing students demographic characteristics with stroke related factors $(\mathrm{N}=144)$.

\begin{tabular}{|c|c|c|c|c|c|c|}
\hline Variables & Age & Religion & $\begin{array}{l}\text { Risk } \\
\text { Factor }\end{array}$ & $\begin{array}{c}\text { Warning } \\
\text { Signs }\end{array}$ & $\begin{array}{c}\text { First } \\
\text { Responses }\end{array}$ & $\begin{array}{c}\text { Special } \\
\text { Management }\end{array}$ \\
\hline Age & 1 & -0.090 & $-0.181^{*}$ & -0.162 & -0.043 & -0.032 \\
\hline Religion & -0.090 & 1 & $0.183^{*}$ & 0.143 & 0.036 & -0.072 \\
\hline Risk Factors & $-0.181^{*}$ & $0.183^{*}$ & 1 & $0.247^{* *}$ & 0.043 & 0.139 \\
\hline Warning signs & -0.162 & 0.143 & $0.247^{* *}$ & 1 & 0.090 & -0.031 \\
\hline First Responses & -0.043 & 0.036 & 0.043 & 0.090 & 1 & 0.080 \\
\hline $\begin{array}{c}\text { Special } \\
\text { Management }\end{array}$ & -0.032 & -0.072 & 0.139 & -0.031 & 0.080 & 1 \\
\hline
\end{tabular}

correlated with their age $\left(\mathrm{r}=-0.181^{\star}, \mathrm{p}=0.033\right)$, meaning that younger students were less aware of stroke risk factors. Muslim students $\left(r=0.183^{\star}, p=0.031\right)$ were more likely to be aware of stroke risk factors. No relationship between age, and awareness of stroke risk factors, awareness of stroke warning signs and behaviors of first responses to strokes and behaviors of special stroke patient managements were found. 


\section{Discussion}

The purpose of this study was to explore fourth-year undergraduate nursing students' awareness of stroke and stroke management behaviors. The results of this study have shown that the majority of students have substantial gaps in their awareness of stroke-related information and special stroke patient management behaviors, but had a moderate level of awareness of stroke risk factors. Despite differences in educational settings, curricula, and practice environment between Korea and Bangladesh, the results of this study were consistent with the Korean study [22] in which fourth-year undergraduate nursing students' scores indicated moderate awareness of stroke risk factors $(\mathrm{M}=76.49, \mathrm{SD}=12.77)$. A U.K. study [16] yielded similar results wherein most of the nursing students (91.5\%) had a very low level of awareness about the risk factors for stroke.

The majority of the students in this study demonstrated a very low level of awareness of the warning signs of a stroke. This result was also consistent with the Korean study [22], which revealed that a majority of the participants had a low level of awareness about the warning signs of stroke $(\mathrm{M}=34.72, \mathrm{SD}=$ 12.75). A U.K. study of third-year nursing students showed that a majority of them had an unacceptable level of awareness about common stroke symptoms [16].

The possible reasons why the students in these studies may not have had higher levels of awareness of stroke risk factors and warning signs are that the content included in the curriculum did not convey up-to-date information about strokes, or that their work-based education was inadequate. These conditions might have precluded the students from reaching higher levels of cognitive and affective domains in terms of awareness of stroke risk factors and warning signs. Multifaceted stroke education is needed for nursing students to enhance their awareness of stroke risk factors and warning signs [22].

Nursing students were observed to have a very low level of behaviors of special stroke patient managements. In this study, nursing students' low level of behaviors of special stroke patient managements was correlated with their relatively low awareness of stroke warning signs and risk factors. These results are in accord with the KAP model's predictions [19], the findings from the Korean study, and the previous study conducted in the U.K. [16]. The U.K. study showed that $78 \%$ of students' awareness of stroke risk factors was largely incorrect, which decreased their clinical practice capabilities.

There are several possibilities for explaining this very low level of behaviors. First, students had inadequate time to study or were presented with little up-todate stroke-related information in their curricula. The absence of a work-based education program to prepare students for their transition between theoretical and practicum courses was likely a large contributing factor to the students' very low level of stroke management behaviors. According to Edwards [15], nurses working with stroke patients often felt ill-prepared with their level of awareness in any setting or specialty when describing their pre-registration education.

This study found a statistically significantly positive correlation between nurs- 
ing students' awareness of stroke risk factors and stroke warning signs ( $\mathrm{r}=$ $0.247, \mathrm{p}<0.05)$. This relationship was similar with those found in the Korean study. The findings of the Korean study revealed the positive correlation between awareness of stroke risk factors and awareness of stroke warning signs with behaviors of first responses to strokes and special stroke patent managements behaviors. However, this study found no such connection. Students' age was negatively correlated with their awareness of stroke risk factors, which was not found by the Korean study. Muslim students had higher awareness of stroke risk factors, which was not found by the Korean study. The U.K. and Korean studies found the same relationships between students' awareness of stroke risk factors and stroke management behaviors.

The students' inadequate awareness of stroke risk factors and warning signs was reflected in their very low level of behaviors of special stroke patient managements [16]. The Korean study similarly found that adults with low to moderate awareness of stroke risk factors and warning signs had significantly poorer ability of how to react to strokes [22].

Overall, in accordance with the KAP model's predictions, nursing students with low awareness of stroke risk factors and stroke warning signs also had a low behavior of stroke patient management. No significant correlation was found between age, awareness of stroke risk factors, and awareness of stroke warning signs and behaviors of stroke management. This result may have been due to an absence of updated information on stroke management in the students' curricula or lack of practicum preparation.

\subsection{Implications}

The outcomes of this study have implications for nursing education, practice, and future research in Bangladesh. It provides baseline data for current curriculum performance that curriculum committees can use to redesign nursing curricula to better educate nursing students about strokes. Work-based educational programs could help nursing students enhance their awareness of and behaviors regarding stroke.

\subsection{Opportunities for Further Studies}

Replication of this study in other settings is recommended to promote the generalizability of the findings above. A further study of stroke educational programs should be conducted to examine students' awareness of and behaviors regarding stroke.

\subsection{Study Limitations}

The main limitation of this study was that it used a self-reporting questionnaire to examine nursing students' awareness of and behavior regarding strokes management. So the responses might not reflect actual stroke management behaviors. The generalizability of the study results is compromised by the small sample size and the fact that it sampled only two university populations. 


\section{Conclusion}

A descriptive study was conducted to explore the level of fourth-year undergraduate nursing students' awareness and behavior regarding strokes. The relationships between these variables were examined. The findings showed that students had moderate awareness levels of stroke risk factors, but very low awareness levels of stroke warning signs. The results also indicated that students had obtained very low levels of behaviors of first responses to strokes and special stroke patient managements behaviors. It can be reasonably assumed that nursing students' inadequate stroke awareness was reflected in their poor execution of stroke management. Work-based education is a necessary part of nursing curricula to increase nursing students' awareness and behaviors regarding strokes as part of their practicum preparedness.

\section{References}

[1] Islam, M.N., Moniruzzaman, M., Khalil, M.I., Bashir, R., Alam, M.K., Loo, K.W., et al. (2013) Barden of Stroke in Bangladesh. International Journal of Stroke, 8, 211215. https://doi.org/10.1111/j.1747-4949.2012.00885.x

[2] Lindsay, P., Bayley, M., Hellings, C., Hill, M., Woodbury, E. and Phillips, S. (2008) Canadian Best Practice Recommendations for Stroke Care. Canadian Medical Association Journal, 2, 179-191.

[3] World Health Organization (2012) WHO Countries Database. Urban Health Profile, Bangladesh.

[4] Mateen, F.J., Carone, M., Alam, N., Streatfield, P.K. and Black, R.E. (2012) A Population Based Case Control Study of 1250 Stroke Deaths in Rural Bangladesh. European Journal of Neurology, 19, 999-1006. https://doi.org/10.1111/j.1468-1331.2012.03666.x

[5] Michael, K.M. and Shaughnessy, M. (2006) Stroke Prevention and Management in Older Adults. Journal of Cardiovascular Nursing, 21, 21-26. https://doi.org/10.1097/00005082-200609001-00006

[6] Mackay, J, and Mansah, G.A. (2004) The Atlas of Heart Disease and Stroke. World Health Organization, Geneva.

[7] Harper, J.P. (2007) Emergency Nurses Knowledge of Evidence-Based Ischemic Stroke Care: A Pilot Study. Journal of Emergency Nursing, 33, 202-207. https://doi.org/10.1016/j.jen.2006.11.002

[8] Neau, J.P., Ingrand, P. and Godeneche, G. (2009) Awareness within the French Population Concerning Stroke Signs, Symptoms, and Risk Factors. Clinical Neurological Neurosurgery, 111, 659-664. https://doi.org/10.1016/j.clineuro.2009.05.015

[9] Yoon, S.S., Heller, R.F., Levi, C., Wiggers, J. and Fitzgerald, P.E. (2001) Knowledge of Stroke Risk Factors, Warning Symptoms, and Treatment Among an Australian Urban Population. Stroke, 32, 1926-1930. https://doi.org/10.1161/01.STR.32.8.1926

[10] Campos Sousa, R.N., Soares, V.Y., Almeida, K.J., Carvalho, L.I., Jacobina, K.S., Athayde Netto, A.E., et al. (2007) Knowledge of Stroke Among a Brazilian Urban Population. Arq Neuropsiquiatr, 65, 587-591. https://doi.org/10.1590/S0004-282X2007000400007

[11] Pandian, J.D., Jaison, A., Deepak, S.S., Kalra, G., Shamsher, S., Lincoln, D.J., et al. (2005) Public Awareness of Warning Symptoms, Risk Factors, and Treatment of Stroke in Northwest India. Stroke, 36, 644-648. 
https://doi.org/10.1161/01.STR.0000154876.08468.a0

[12] Das, K., Mondal, G.P., Dutta, A.K., Mukherjee, B. and Mukherjee, B.B. (2007) Awareness of Warning Symptoms and Risk Factors of Stroke in the General Population and in Survivors Stroke. Journal of Clinical Neuroscience, 14, 12-16. https://doi.org/10.1016/j.jocn.2005.12.049

[13] Das, S., and Das, S.K. (2013) Knowledge, Attitude and Practice of Stroke in India versus other Developed and Developing Countries. Annals of Indian Academy of Neurology, 16, 488-493. https://doi.org/10.4103/0972-2327.120431

[14] Baker, M. (2012) Education Requirements for Nurses Working with People with Complex Neurological Conditions: Nurses' Perceptions. Nurse Education Today, 41, 71-77. https://doi.org/10.1016/j.nedt.2011.01.011

[15] Edwards, G. (2006) The Training and Education of Nurses Working in Stroke Care. The British Journal of Nursing, 15, 1180-1184. https://doi.org/10.12968/bjon.2006.15.21.22377

[16] Mason-Whitehead, E. and Janet Barton, V.R. (2013) Passed Without a Stroke: A UK Mixed Method Study Exploring Student Nurses' Knowledge of Stroke. Nurse Education Today, 33, 998-1002. https://doi.org/10.1016/j.nedt.2012.07.021

[17] Bloom, B.S. (1956) Taxonomy of Educational Objectives, the Classification of Educational Goals-Handbook I: Cognitive Domain. David McKay, New York.

[18] Anderson, L.W. and Krathwohl, D.R. (2001) A Taxonomy for Learning, Teaching and Assessing: A Revision of Bloom's Taxonomy of Educational Objectives: Complete Edition. Longman, New York.

[19] Launiala, A. (2009) How Much Can a KAP Survey Tell Us about People Knowledge, Attitude, and Practice? Some Observations from Medical Anthropology Research on Malaria in Pregnancy in Malawi. Anthropology Maternal Journal, 11, 1-13.

[20] Krathwohl, D.R., Bloom, B.S. and Massia, B.B. (1964) Taxonomy of Educational Objectives, the Classification of Educational Goals-Handbook II: Affective Domain. David McKay, New York.

[21] Polit, D.H. and Beck, C.T. (2008) Nursing Research: Generated and Assessing Evidence for Nursing Practice. 8th Edition, Lippincott Williams \& Wilkins, Philadelphia, New York.

[22] Kim, K.H., Jeong, S.H. and Kang, H.C. (2014) Identification of Subgroups with Lower Level of Stroke Knowledge Using Decision-Tree Analysis. Journal of Korean Academic Nursing, 44, 97-107. https://doi.org/10.4040/jkan.2014.44.1.97 
Submit or recommend next manuscript to SCIRP and we will provide best service for you:

Accepting pre-submission inquiries through Email, Facebook, LinkedIn, Twitter, etc. A wide selection of journals (inclusive of 9 subjects, more than 200 journals)

Providing 24-hour high-quality service

User-friendly online submission system

Fair and swift peer-review system

Efficient typesetting and proofreading procedure

Display of the result of downloads and visits, as well as the number of cited articles Maximum dissemination of your research work

Submit your manuscript at: http://papersubmission.scirp.org/

Or contact ojn@scirp.org 